\title{
Study and Isolation of Yeast from Industrial Food Waste Peel and the Metal Effectiveness on Ethanol Production Using Various Metals lons
}

\author{
Akshay Chaturvedi and Pratibha Teotia* \\ Department of Biotechnology (SET), Noida International University, Greater Noida, U.P, India. \\ Corresponding author email: pratibha.teotia@niu.edu.in
}

\section{ABSTRACT}

This research work explores the potential for the isolation and use of yeast from industrial food waste i.e., here pineapple and cherry peel-based ethanol bioprocesses. The process of fermentation has a long history in the production of Bioethanol. Bioethanol is the best alternative source of clean and renewable sources of energy and the only winner in this category. The objective of this research work was to isolate and characterize high potential ethanol producing yeast strains from industrial fruit peel waste. Two yeast isolates from $(\mathrm{Ch})$ and $(\mathrm{P})$ have been isolated, both yeasts have been characterized and identified on the basis of characteristics and optimized on ethanol producing capabilities using substrates. The highest production by using the yeasts was $7.12 \%$ and $5.22 \%$ for $\mathrm{P}$ and $\mathrm{Ch}$, at $\mathrm{pH} 5.5$, at $30^{\circ} \mathrm{C}$ temperature in medium. Metal ions helped to increase the highest rate of ethanol production is 09.56\% by KH2P04. This research work revealed that these yeast isolates can also be used to benefit the industrial production of alcohol and also help into the benefit of fuel demand.

KEY WORDS: BIOETHANOL, INDUSTRIAL WASTE, FERMENTATION, MICROBIOLOGY, WASTE MANAGEMENT.

\section{INTRODUCTION}

Bioethanol is the most common and most widely used type of biofuel, that is basically ethyl alcohol, the same type of alcohol found in beverage alcohol. Which can also be used as fuel or as motor fuel, it is most often used mainly as a biofuel additive for gasoline. As a form of renewable energy source that can be generated or produced using agricultural feedstock or can also be produced using food industrial waste as a feedstock. During the ethanol production or fermentation, the different types of sugars mainly glucose (in substrate) are converted into ethanol and carbon-dioxide. The basis for the production of ethanol is microbial fermentation of sugar by yeast.

Biosc Biotech Res Comm P-ISSN: 0974-6455 E-ISSN: 2321-4007

\section{crossef}

Identifiers and Pagination

Year: 2021 Vol: 14 No (9) Special Issue

Pages: $91-95$

This is an open access article under Creative

Commons License Attribn 4.0 Intl (CC-BY). DOI: $h t t p: / / d x$.doi.org/10.21786/bbrc/14.9.20
Compared to other types of microorganism's yeast, specifically Saccharomyces cerevisiae is the most common microbe for the production of ethanol, due to its high production of ethanol capacity. In this study the Saccharomyces cerevisiae were selected as production microbes on account of their availability and after detailed study and characterization and optimization of parameters.

\section{MATERIAL AND METHODS}

Collection of Raw Material: Collection of Fruit waste (Peel) from Food processing industry for the isolation of Yeast from mainly Pineapple (P) and Cherry (Ch) peel which is denoted as $\mathrm{Ch}$ and $\mathrm{P}$.

Other instruments are: Autoclave for sterilization, spectrophotometer, Laminar air flow (Biosafety Chamber), Shakin and Non-Shaking incubator for incubation, test tubes, petri plates and many more.

Isolation and screening of Yeast: Fruit samples from waste (Cherry and pineapple) were collected from local food processing industry basically from canning unit, and then
Article Information

Received: $15^{\text {th }}$ Apr 2021 ccepted after revision: $25^{\text {th }}$ June 2021 
their peels were extracted. And then the isolation is done by using the procedure from (Lee, 2018), Single colony formed was to be picked, and the cells were observed under a compound microscope. (Brooks, 2008)

Culture maintenance: The maintenance of culture was done by slants subculturing using YMM, incubating for 2 days at 28 to $3^{\circ} \mathrm{C}$, thereafter, use refrigerator for further storage at -5 to $-9{ }^{\circ} \mathrm{C}$ for future use as per the requirement.

Growth of Isolates: In this current study the selected isolates, the morphology of cells of and their appearance on YEPD (yeast extract peptone dextrose) agar media was examined (Ortiz-Muñiz, 2010). The medium was then sterilized at $121{ }^{\circ} \mathrm{C}$ at $15 \mathrm{psi}$ and poured on a petri dish and cooled down (Gamborg, 1995). 2 days old yeast strain than incubated at $30{ }^{\circ} \mathrm{C} \pm 2$ for 2 days. Features of the appearance of cultures were recorded.
The isolates $\mathrm{Ch}$ and $\mathrm{P}$ were cultured in YEPD (yeast extract peptone dextrose) liquid medium. Incubated at $28-32{ }^{\circ} \mathrm{C}$ for $72 \mathrm{hr}$. The culture for the growth is to examined visually on the surface of liquid medium, and the shape of cells using compound microscope (Lorenz, 2000) (Magnus,India)

Carbohydrate's fermentation: The fermentation ability of seven different carbohydrates by selected isolates (Miller, 1959) (Ch \& P) was examined anaerobically and is assessed by looking for the formation of gas (CO2) in Durham tube and change in colour of the fermentation media.; the media colour changed from red to yellow due to the formation of gas and acid produce.. The medium was prepared by using these- peptone (10 gm), $\mathrm{NaCl}$ (5 gm), phenol red (Indicator) and carbohydrate (5 gm). A volume of $15 \mathrm{ml}$ aliquots dispensed in different tubes were then autoclaved, after cooling 2 days old selected yeast strain.

\begin{tabular}{|l|c|c|c|}
\hline \multirow{2}{*}{ Table 1. Fermentation of different carbohydrates using P isolate } \\
\hline \multirow{2}{*}{$\begin{array}{l}\text { Carbohydrate } \\
\text { (Sugar) }\end{array}$} & $\begin{array}{c}\text { Colour of the medium } \\
\text { Before Fermentation }\end{array}$ & After Fermentation \\
\cline { 3 - 4 } & Pink colour & Colour of the medium & Production of gas \\
\hline Glucose & Pink colour & (yellow) & yes \\
\hline Sucrose & Pink colour & (Yellow) & yes \\
\hline Maltose & Pink colour & (No change in colour) & no \\
\hline Lactose & Pink colour & (yellow) & yes \\
\hline Fructose & Pink colour & Yellow & yes \\
\hline Xylose & Pink colour & Yellow & yes \\
\hline Trehalose & & & \\
\hline
\end{tabular}

\begin{tabular}{|c|c|c|c|}
\hline \multirow{2}{*}{$\begin{array}{l}\text { Carbohydrate } \\
\text { (Sugar) }\end{array}$} & \multirow{2}{*}{$\begin{array}{l}\text { Colour of the medium } \\
\text { Before Fermentation }\end{array}$} & \multicolumn{2}{|c|}{ After Fermentation } \\
\hline & & Colour of the medium & Production of gas \\
\hline Glucose & Pink colour & (yellow) & yes \\
\hline Sucrose & Pink colour & (yellow) & yes \\
\hline Maltose & Pink colour & (yellow) & no \\
\hline Lactose & Pink colour & (No change in colour) & no \\
\hline Fructose & Pink colour & (yellow) & no \\
\hline Xylose & Pink colour & (No change in colour) & no \\
\hline Trehalose & Pink colour & (yellow) & yes \\
\hline
\end{tabular}

Table 3. Growth of $\mathrm{Ch}$ yeast isolate in liquid media with different temperatures

\begin{tabular}{|c|c|c|c|}
\hline Temperature & Initial & $\begin{array}{l}\text { optical density } \\
(O . D)\end{array}$ & $\begin{array}{c}\text { O.D (after 2- days of } \\
\text { growth) }\end{array}$ \\
\hline $25^{\circ} \mathrm{C}$ & .240 & & 1.365 \\
\hline $30^{\circ} \mathrm{C}$ & .342 & & 1.427 \\
\hline $32^{\circ} \mathrm{C}$ & .328 & & 1.650 \\
\hline $37^{\circ} \mathrm{C}$ & .439 & & 1.987 \\
\hline $40^{\circ} \mathrm{C}$ & .458 & & 2.001 \\
\hline $45^{\circ} \mathrm{C}$ & .489 & & .681 \\
\hline
\end{tabular}

Table 4

\begin{tabular}{|c|c|c|c|}
\hline Temp erature & Initial & $\begin{array}{l}\text { optical density } \\
\text { (O.D) }\end{array}$ & $\begin{array}{c}\text { O.D (after 2-days of } \\
\text { grow th) }\end{array}$ \\
\hline $25^{\circ} \mathrm{C}$ & .323 & & 1.002 \\
\hline $30^{\circ} \mathrm{C}$ & .202 & & .695 \\
\hline $32^{\circ} \mathrm{C}$ & .265 & & 1.322 \\
\hline $37^{\circ} \mathrm{C}$ & .582 & & 2.890 \\
\hline $40^{\circ} \mathrm{C}$ & .552 & & 2.154 \\
\hline $44^{\circ} \mathrm{C}$ & .511 & & .496 \\
\hline
\end{tabular}


Thermotolerance detection: YEPD liquid medium is used for thermotolerance detection and growth in liquid media of selected yeast isolates of cherry and pineapple. The medium was Sterilized and cooled. Medium was distributed into tubes and after that inoculated 2-days selected yeast isolates (Ch \& P). The initial (O.D) of each tube is recorded by using spectrophotometer at 600 $\mathrm{nm}$ against the medium as blank (control sample). The increase in O.D in a tube was recorded as evidence of growth. The growth in YEPD agar medium at different temperature to ensure the strains thermotolerance.

Growth at different $\mathrm{pH}$ in liquid media: YEPD liquid media is used to find out the ability to grow on different $\mathrm{pH}$. The media was sterilized by autoclaving and then cooled. YEPD broth mediaum is prepared at different $\mathrm{pH}$ which are 2-10. Then, each was inoculated with the yeast (the initial 0.D at $600 \mathrm{~nm}$ was to be measured) and then incubated at $30^{\circ} \mathrm{C}$ for 2 days. After 2 days the cell density was further recorded at $600 \mathrm{~nm}$ for the growth.

Table 5. P (Pineapple) isolate in liquid media with different $\mathrm{pH}$ growth

\begin{tabular}{ccc|}
\hline $\mathrm{pH}$ & $\begin{array}{c}\text { Initial op tical density } \\
(\text { O.D) }\end{array}$ & $\begin{array}{c}\text { O.D (after 2-days of } \\
\text { growth) }\end{array}$ \\
\hline $\mathbf{2}$ & .333 & .899 \\
$\mathbf{3}$ & .428 & 1.866 \\
$\mathbf{4}$ & .345 & 1.870 \\
\hline 6 & .390 & 1.788 \\
\hline $\mathbf{7}$ & .184 & 1.489 \\
\hline 8 & .259 & 1.455 \\
\hline $\mathbf{9}$ & .277 & 1.219 \\
\hline 10 & .422 & 1.326 \\
\hline
\end{tabular}

Table 6. Ch (Cherry) isolate in liquid media with different $\mathrm{pH}$ growth

\begin{tabular}{ccc|}
\hline $\mathrm{pH}$ & $\begin{array}{c}\text { Initial optical density } \\
(\text { O.D) }\end{array}$ & $\begin{array}{c}\text { O.D (after 2-days of } \\
\text { grow th) }\end{array}$ \\
\hline $\mathbf{2}$ & 342 & .840 \\
$\mathbf{3}$ & .389 & 1.457 \\
$\mathbf{4}$ & .269 & 1.379 \\
6 & .309 & 1.470 \\
7 & .200 & 1.366 \\
8 & .220 & 1.270 \\
9 & .209 & 1.222 \\
10 & .428 & 1.203 \\
\hline
\end{tabular}

Observation of Osmotolerance: YEPD broth was prepared containing with different range in between 6\%- 20\% of $\mathrm{NaCl}$. Each tube contained $10 \mathrm{ml}$ of YEPD liquid media with appropriate concentration of $\mathrm{NaCl}$, and the blank media were used as a control sample. Then, each was inoculated of the yeast cell (the initial O.D at $600 \mathrm{~nm}$ was measured) and then incubated at $28-30{ }^{\circ} \mathrm{C}$ for 2 days. After, cell density was further recorded by spectrophotometer at $600 \mathrm{~nm}$.

Molasses fermentation: Molasses fermentation is done in the conical flasks. A total of $200 \mathrm{ml}$ of fermentation medium is taken into the $500 \mathrm{ml}$ of flasks and then the suspension of yeast was inoculated into the medium in an aseptic condition and then incubated at different temperatures in an incubator under non-shaking (N.S) and shaking (S) conditions.

Effect of sugar concentration: The effect of concentration of sugar in ethanol production by S. cerevisiae were studied, media is prepared by molasses dilution to reducing sugar concentration which ranges between $04.5 \%$ to $07 \%$, and fermentation is carried out of $200 \mathrm{ml}$ medium in to $500-\mathrm{ml}$ conical flask. Inoculate is added in to the medium. After that Samples were withdrawn at different times and estimated for residual sugars as well as ethanol content in the medium (Miller, 1959).

Table 7. $\mathrm{P}$ isolate in liquid media with different $\mathrm{NaCl}$ concentration

\begin{tabular}{ccc|}
\hline $\mathrm{NaCl}$ percentage & $\begin{array}{c}\text { Initial opticaldensity } \\
\text { (O.D) }\end{array}$ & $\begin{array}{c}\text { O.D (after 2-days of } \\
\text { growth) }\end{array}$ \\
\hline $\mathbf{6 \%}$ & .235 & 1.365 \\
$\mathbf{9 0 \%}$ & .217 & .645 \\
$\mathbf{1 2 \%}$ & .259 & .423 \\
$\mathbf{1 5 \%}$ & .208 & .289 \\
$\mathbf{1 8 \%}$ & .259 & .271 \\
$\mathbf{2 0 \%}$ & .257 & .240 \\
\hline
\end{tabular}

Table 8. Ch (cherry) isolate in liquid media with different $\mathrm{NaCl}$ concentration

\begin{tabular}{ccc|}
\hline $\mathrm{NaC}_{\mathrm{a}}$ percentage & $\begin{array}{c}\text { Initial optical density } \\
(\mathrm{O} . \mathrm{D})\end{array}$ & $\mathrm{O}$.D (after 2 days of grouth) \\
\hline $6 \%$ & .209 & .872 \\
\hline $9 \%$ & .227 & .239 \\
$12 \%$ & .239 & .250 \\
$15 \%$ & .187 & .149 \\
$18 \%$ & .285 & .178 \\
\hline $20 \%$ & .251 & .189 \\
\hline
\end{tabular}

pH effect: To study the $\mathrm{pH}$ effect on ethanol production by $\mathrm{S}$. cerevisiae, fermentation media with different reducing concentration of sugar were used for the production of ethanol. Fermentation is carried out at pH 05.0 in of $200 \mathrm{ml}$ media in a $500-\mathrm{ml}$ conical flask. A 2-day-old inoculum is added to the media. Samples were than withdrawn at different times and estimated for residual sugars as well as ethanol content in the medium.

Effect of metals: For determination of the effects of metals on ethanol production which are $\mathrm{MnCl} 2$, $\mathrm{ZnSO} 4$, CuSO4, $\mathrm{KH} 2 \mathrm{PO} 4$, and were added at different concentrations and then the fermentation was carried out in the presence of different types of metals. Observation of ethanol production was done at the temperature of 30 ${ }^{\circ} \mathrm{C}, \mathrm{pH}$ 5.0, and using the reducing sugar concentration of $7.0 \%$ in shaking (S) condition.

\section{RESULTS}

Growth of isolates: The morphology of yeast cells was observed grown in solid media and on liquid media according to the standard method using microscope. Six petri dishes are used to confirm the identification of the 
cell morphology of cherry and pineapple yeast isolates under compound microscope.

Carbohydrate's fermentation: Here, S. cerevisiae shows variations in terms of utilization of different sugars in the below Tables 1 \& 2 . The isolated strain utilises all seven sugars but failed to grow on lactose. Change in the colour of the media confirmed the fermentation. The results were recorded after 2-days of inoculation.

\section{Different environmental conditions to check the yeast Tolerance}

Temperature effects on growth: YEPD agar plates containing yeast cell were incubated for 2-days at different temperature. Both isolates were able to grow at $25-45^{\circ} \mathrm{C}$. Thermotolerance were repeated in liquid media, for the confirmation of results obtained from the solid media, Table-3, Growth of P yeast isolate in liquid media at different temperatures From the table-3, that shows the $P$ yeast isolate is highly thermotolerant because it is able to grow up to $45^{\circ} \mathrm{C}$, From the table-4, which shows that the $\mathrm{Ch}$ yeast isolate is highly thermotolerant also as it is able to grow up to $40^{\circ} \mathrm{C}$.

pH effect on growth: Both the isolates of $\mathrm{Ch}$ and $\mathrm{P}$ shows the ability to grow in a wider range of $\mathrm{pH}$, from between two to ten. Both isolates with $\mathrm{pH} 10$, but $\mathrm{pH} 04.0$ for $\mathrm{P}$ isolate and $\mathrm{pH} 6$ for $\mathrm{Ch}$ isolate shows the optimum and best result. After 2-days, the cell optical density is recorded at $600 \mathrm{~nm}$ and given gradually for evidence of growth in the below table- 5 and 6 .
Observation of Osmotolerance: The pineapple $(\mathrm{P})$ isolates tolerate up to $09 \% \mathrm{NaCl}$ successfully in the medium, and this was seen an index of osmotolerance. But at the higher concentration, the growth is reduced with accordance to time. The isolate of cherry (C) showed optimum at up to $12 \% \mathrm{NaCl}$ concentration.

Ethanol production: The results of ethanol production and its tolerance at different concentration of sugars at $30{ }^{\circ} \mathrm{C}$ and $\mathrm{pH} 05$ in shaking (S) and non-shaking (N.S) condition, Pineapple (P) yeast shows good results than the Cherry (C). Thus, some series of experiments are conducted at different-different physicochemical conditions for the optimization of ethanol production by the Pineapple isolate. For the optimum result, shaking condition experiments were carried out and the result can be seen in the below table- 9 .

Metal ions effect on ethanol production: Ethanol production optimization by additional nutrient supplements as effect of metals such as $\mathrm{MnCl} 2$ (Manganese (II) chloride), CuSO4 (Copper (II) sulphate), KH2PO4 (Potassium dihydrogen phosphate), and ZnSO4 (Zinc Sulphate) was analysed. Both cherry and pineapple isolates show high productivity after adding of supplements, as studied. The highest ethanol production observed is $09.56 \%$ by $\mathrm{P}$ isolate with $\mathrm{KH} 2 \mathrm{PO} 4$ supplements in shaking condition (Nasir, 2017) shown in below graph fig.2. Ch isolate produced 8\% ethanol after $\mathrm{MnCl} 2$ supplementation in shaking condition as shown in below graph (fig. 1). the average of all results is shown in below graphs (fig. 1 and fig.2) and in table-10.

Table 9. Under shaking and non-shaking condition ethanol production by $\mathrm{Ch}$ isolate at initial $\mathrm{pH} 5$ and with different sugar concentration. The highest production recorded $5.22 \%$ at sugar concentration of 5.5\%. The data shown are the average of 3 individual experiments under given condition. And for $\mathrm{P}$ isolate the highest production at $7.89 \%$ at sugar concentration of 6.5 .

\begin{tabular}{|l|c|c|c|c|}
\hline $\begin{array}{l}\text { Concentration of glucose } \\
(\%)\end{array}$ & $\begin{array}{c}\text { Cherry } \\
\text { (shaking) }\end{array}$ & $\begin{array}{c}\text { Cherry } \\
\text { (non-shaking) }\end{array}$ & $\begin{array}{c}\text { Pineapple } \\
\text { (shaking) }\end{array}$ & $\begin{array}{c}\text { Pineapple } \\
\text { (non-shaking) }\end{array}$ \\
\hline 4.5 & 2.56 & 0.56 & 3.523 & 2.18 \\
\hline 5.5 & 5.22 & 2.28 & 7.12 & 6. \\
\hline 6 & 4.56 & 4.22 & 5.19 & 3.49 \\
\hline 6.5 & 3.22 & 2.27 & 7.89 & 3 \\
\hline 7 & 3.55 & 3.56 & 5.55 & 3.08 \\
\hline
\end{tabular}

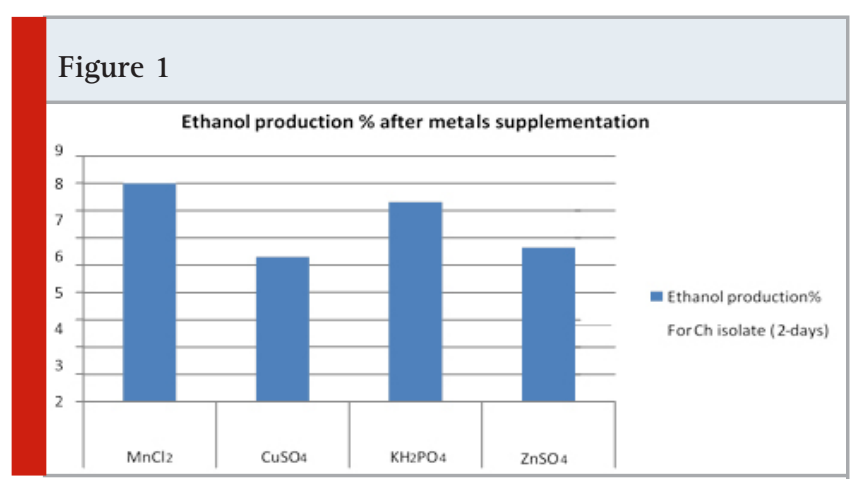

Figure 2

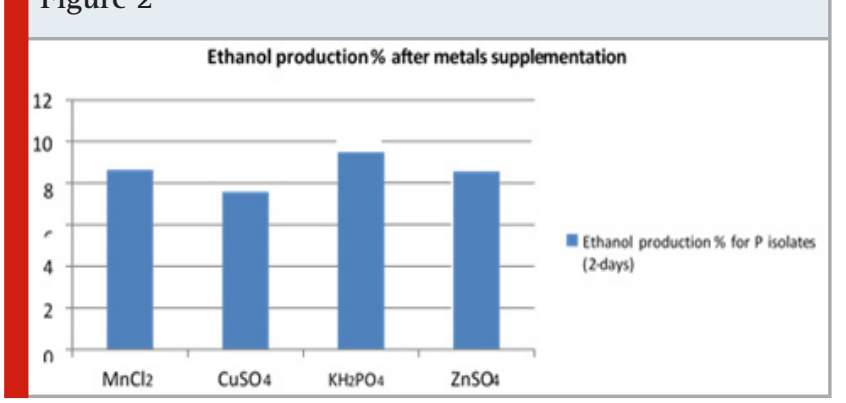


Table 10. Production of ethanol by $\mathrm{P}$ and $\mathrm{Ch}$ isolate in presence of metals

\begin{tabular}{l|c|c} 
Metals ion & Ethanol (\%) by P(2-days) & Ethanol (\%) by Ch isolate (2-days) \\
$\mathrm{MnCl}_{2}$ & 8.8 & 8 \\
\hline $\mathrm{CuSO}_{4}$ & 7.48 & 6.20 \\
\hline $\mathrm{KH}_{2} \mathrm{PO}_{4}$ & 9.56 & 7.40 \\
\hline $\mathrm{ZnSO}_{4}$ & 8.12 & 6.80
\end{tabular}

\section{DISCUSSION}

Both isolates of cherry and pineapple that were found belong to saccharomyces type unicellular. The P isolate shows better tolerance than the $\mathrm{Ch}$ isolate at up to $15 \%$ of $\mathrm{NaCl}$ equivalent of that osmotic pressure. (Lodder, 1970). As we know from past studies that yeasts are mesophilic with upper limit growth temperature between $30 \mathrm{C}$ to $3^{\circ} \mathrm{C}$. This is the reason why the temperature must be maintained between 30 to $35{ }^{\circ} \mathrm{C}$ for fermentation process. The $\mathrm{P}$ yeast shows far better tolerance than of the $\mathrm{Ch}$ peel isolate at up to $15 \% \mathrm{NaCl}$ equivalent of osmotic pressure. This study shows that the highest ethanol production observed is $09.56 \%$ by $\mathrm{P}$ isolate with $\mathrm{KH} 2 \mathrm{PO} 4$ in shaking (S) condition. Ch isolate produced 8\% ethanol after $\mathrm{MnCl} 2$ supplementation in shaking (S) condition. The isolates are tested for fermentation of carbohydrates, P (Pineapple) isolate is able to utilize six out of the seven tested total sugars, and cherry isolate is able to utilize five sugars out of seven, which indicates that both were diverse in sugar utilization that is shown in table-1 \& 2 .

\section{CONCLUSION}

The results reported in the present study revealed that both the $\mathrm{P}$ and $\mathrm{Ch}$ yeast isolates were highly tolerant to ethanol and as well as thermotolerant and osmotolerant, both can survive at various $\mathrm{pH}$ ranges. These results shows that the isolates can be used at industrial and at heigh level for the fermentation of various raw materials in reference to obtain an increased production of bioethanol.

\section{REFERENCES}

Brooks, A., (2008). Ethanol production potential of local yeast strains isolated from ripe banana peels. African journal of Biotechnology, 7(20).

Gamborg, O. a. P. G., (1995). Media Preparation and Handling,Plant Cell, Tissue and Organ Culture. Berlin, Heidelberg: Springer.

Gamborg, O. a. P. G., (1995). Media Preparation and Handling,Plant Cell, Tissue and Organ Culture. Berlin,
Heidelberg: Springer.

Lee, Y. C. Y. L. S. P. J. S. J. P. K. a. K. J., (2018). Screening wild yeast strains for alcohol fermentation from various fruits.. Mycobiology, 39(1), pp. 33-39..

Lee, Y. C. Y. L. S. P. J. S. J. P. K. a. K. J., (2018). Screening wild yeast strains for alcohol fermentation from various fruits.. Mycobiology, 39(1), pp. 33-39..

Lodder, J. a. K.-v. R. N., (1970). General classification of the yeasts, A Taxonomic Study. 2 ed. Amsterdam: The yeasts-a taxonomic study..

Lodder, J. a. K.-v. R. N., (1970). General classification of the yeasts, A Taxonomic Study. 2 ed. Amsterdam: The yeasts-a taxonomic study..

Lorenz, M. C. N. a. H. J., (2000). Characterization of alcohol-induced filamentous growth in Saccharomyces cerevisiae. Molecular biology of the cell, 11(1), pp. 183199.

Lorenz, M. C. N. a. H. J., (2000). Characterization of alcohol-induced filamentous growth in Saccharomyces cerevisiae. Molecular biology of the cell, 11(1), pp. 183199.

Miller, G., (1959). Use of dinitrosalicylic acid reagent for determination of reducing sugar. Analytical chemistry, 31(3), pp. 426-428.

Miller, G., (1959). Use of dinitrosalicylic acid reagent for determination of reducing sugar. Analytical chemistry, 31(3), pp. 426-428.

Nasir, A. R. S. H. M. a. C. N., (2017). Isolation of Saccharomyces cerevisiae from pineapple and orange and study of metal's effectiveness on ethanol production.. European Journal of Microbiology and Immunology, 7(1), pp. 76-91.

Nofemele, Z. S. P. T. A. P. K. a. S. S., (2012). Improvement of ethanol production from sugarcane molasses through enhanced nutrient supplementation using Saccharomyces cerevisiae. Journal of Brewing and Distilling, Issue 3(2), pp. 29-35.

Nofemele, Z. S. P. T. A. P. K. a. S. S., (2012). Improvement of ethanol production from sugarcane molasses through enhanced nutrient supplementation using Saccharomyces cerevisiae. Journal of Brewing and Distilling, Issue 3(2), pp. 29-35.

Ortiz Muñiz, B. C. O. T. B. a. A. M., (2010). Kinetic study on ethanol production using Saccharomyces cerevisiae ITV-01 yeast isolated from sugar cane molasses. Journal of Chemical Technology and Biotechnology, 85(10), pp. 1361-1367.

Ortiz Muñiz, B. C. O. T. B. a. A. M., (2010). Kinetic study on ethanol production using Saccharomyces cerevisiae ITV-01 yeast isolated from sugar cane molasses. Journal of Chemical Technology and Biotechnology, 85(10), pp. 1361-1367. 